\title{
Closed Monteggia's Fracture
}

National Cancer Institute

\section{Source}

National Cancer Institute. Closed Monteggia's Fracture. NCI Thesaurus. Code C34822.

Proximal radial head dislocation in association with a proximal ulnar fracture that does not involve a break in the adjacent skin. 